\title{
Bioinfluence with Infrared Thermal and Electromagnetic Fields as a Therapeutic Approach of Hamsters with Experimental Graffi Myeloid Tumor
}

\author{
Reneta Toshkova $^{1} \quad$ Ignat Ignatov $^{2 *}$ Elisaveta Zvetkova ${ }^{3} \quad$ Georgi Gluhchev $^{4} \quad$ Christos Drossinakis $^{5}$ \\ 1. PhD, MD Professor, Institute of Experimental Morphology, Pathology and Anthropology with Museum, \\ Bulgarian Academy of Science (BAS), Acad. G. Bonchev Street, bl. 25, Sofia 1113, Bulgaria \\ 2. DSc, Professor, Scientific Research Center of Medical Biophysics (SRCMB), \\ N. Kopernik Street, 32, Sofia 1111, Bulgaria \\ 3. $\mathrm{PhD}, \mathrm{MD}$ Assoc. Professor, Institute of Experimental Morphology, Pathology and Anthropology with \\ Museum, Bulgarian Academy of Science (BAS), Acad. G. Bonchev Street, bl. 25, Sofia 1113, Bulgaria \\ 4. PhD, Assoc. Professor; Institute of Information and Communication Technologies, \\ Bulgarian Academy of Science (BAS), Acad. G. Bonchev Street, bl. 2, Sofia 1113, Bulgaria \\ 5. Dr. h.c, Professor, IAWG - INTERNATIONALE Akademie für Wissenschaftliche \\ Geistheilung Königsteiner Str. 61 a, 65929 Frankfurt Höchst, Germany \\ *E-mail of the corresponding author: mbioph@dir.bg
}

\begin{abstract}
The aim_of the present experiments was to study the effect of bioinfluence - Infrared thermal field (ITF) and electromagnetic fields (e.m. fields) on the progression of experimental tumor in hamsters.Spectral analysis methods called Non-equilibrium spectrum (NES) and Differential non-equilibrium spectrum (DNES) for $1 \%$ solutions of blood serum from hamsters with cancer and healthy hamsters were investigated. Drossinakis had an effect on hamsters with cancer. Results are obtained with the DNES method compared to the control serum samples of hamsters with cancer and healthy hamsters. The spectrum was obtained in the range $\quad(-0.0937 \mathrm{eV} ; 13.23 \mu \mathrm{m}$; $\left.755 \mathrm{~cm}^{-1}\right)-\left(-0.1387 \mathrm{eV} ; 8.95 ; \mu \mathrm{m} ; 1117 \mathrm{~cm}^{-1}\right)$. The average energy $\left(\Delta \mathrm{E}_{\mathrm{H} . . . \mathrm{O}}\right)$ of hydrogen H...O-bonds among individual molecules $\mathrm{H}_{2} \mathrm{O}$ after treatment of Drossinakis was measured by NES- and DNES-methods. The result $\Delta \mathrm{E}=-0.0071 \pm 0.0011 \mathrm{eV}$ is according control serum samples of hamsters with cancer and $\Delta \mathrm{E}=-0.0035 \pm 0.0011 \mathrm{eV}$ is for healthy ones. These results suggest the restructuring of $\Delta \mathrm{E}_{\mathrm{H} \ldots \mathrm{O}}$ values among $\mathrm{H}_{2} \mathrm{O}$ molecules with a statistically reliable increase of local extremums in DNES-spectra. Local extremum was obtained at $(-0.1212) \mathrm{eV}$, which is an indicator of anti-inflammatory effect. Another local extremum was obtained at $(-0.1387) \mathrm{eV}$, which is an indicator of inhibition of development of tumor cells at the molecular level. The effects of Drossinakis influence- anti-inflammatory, antioxidant, and cancer development inhibition are shown. This article deals with the review of the basic biophysical-biochemical and biological processes underlying the influence of Drossinakis. The authors are studying their physical-chemical properties and biophysical and biological effects on the organism of hamsters. Another research by Toshkova has shown that the life span of cancer hamsters influenced by Drossinakis has been increased.
\end{abstract}

Keywords: Infrared thermal field (ITF), electromagnetic fields (e.m. fields), experimental Graffi solid tumor DOI: $10.7176 / \mathrm{JNSR} / 9-4-01$

\section{Introduction}

The strong bio-influence of Drossinakis has been proved via the application of the methods biophotons (Popp), thermovision (Schlebusch), spectrum analysis of water (Antonov, Ignatov), color coronal spectral analysis (Ignatov), gas discharge visualization (Korotkov), synchronizing of brain electromagnetic waves (Li Gendinovich) etc. at more than 80 institutes and centers in Europe. Drossinakis has achieved the following results according the norm - biophoton emission (Popp) ( 900 biophotons $\left.1 \mathrm{~cm}^{2} / 1 \mathrm{~s}\right)$, (norm $\sim 85$ photones, $\left.1 \mathrm{~cm}^{2} / 1 \mathrm{~s}\right)$; increasing of the temperature after bioinfluence (Schlebusch) $\left(1.6-1.8^{\circ} \mathrm{C}\right)$ (norm $0.1^{\circ} \mathrm{C}$ ); average energy of hydrogen bonds among water molecules according control sample (Antonov, Ignatov) $( \pm 8.2 \mathrm{meV})( \pm 1.1 \mathrm{meV})$ etc.

In the current study was followed the effect of influence with Infrared thermal field (ITF) and electromagnetic fields (e.m. fields) of Christos Drossinakis over the experimental myeloid tumor of Graffi, implanted in hamsters. The study was conducted by a team under the authority of Reneta Toshkova.

Purpose of the research: To establish the therapeutic effect of infrared thermal field and e.m. fields in hamsters with experimental tumor.

\section{Experimental design}

2. Methods

2.1. Experimental animals

Hamsters, breed "Golden Syrian", aged 2-4 months with weight around 90-100 g, delivered from breeding 
organization - Slivnitza - Bulgarian Academy of Sciences (BAS) were used in the trials. The animals were grown in standard conditions in the vivarium of the Institute of experimental morphology, pathology and anthropology with museum IEMPAM - BAS, in individual plastic cages with free access to food and water.

\subsection{Experimental tumor model}

The experimental Graffi solid tumor was supported once monthly in hamsters from the research team at IEMPAMBAS (Toshkova, 1995) via subcutaneous transplantation of tumor cells $\left(1-2.10^{6}\right)$ in the back. Between days 7 and 15 after the injection of tumor cells tumor appears, grows progressively and the hamsters die around 30-35 days. In this tumor model, $100 \%$ tumor transplantation and $100 \%$ mortality were observed. No spontaneous tumor's regression was observed.

\subsection{Hematology examination}

Blood smears from Graffi tumour-bearing /control-/ hamsters as well as from the experimental animals /bioinfluenced simultaneously with tumors' implantation/, have been prepared, stained by May-Gruenwald Giemsa method and examined light-microscopically.

\subsection{Ethical aspects:}

All experiments were conducted in accordance with the European convention for protection of vertebrate animals, used for experimental and other scientific purposes (OJ L 222) and approved from the National Veterinary Medical Office.

\subsection{NES and DNES Spectral Analysis}

The device for DNES spectral analysis based on an optical principle was designed by A. Antonov. For this, a hermetic camera for evaporation of water drops under stable temperature $\left(+22-24{ }^{0} \mathrm{C}\right)$ conditions was used. The water drops were placed on a water-proof transparent pad, which consisted of thin maylar folio and a glass plate. The light was monochromatic with filter for yellow color with wavelength at $\lambda=580 \pm 7 \mathrm{~nm}$. The device measures the angle of evaporation of water drops from $72.3^{0}$ to $0^{0}$. The DNES-spectrum was measured in the range of $-0.08-$ $-0.1387 \mathrm{eV}$ or $\lambda=8.9-13.8 \mu \mathrm{m}$ using a specially designed computer program. The main estimation criterion in these studies was the average energy $\left(\Delta \mathrm{E}_{\mathrm{H}} \ldots \mathrm{O}\right)$ of hydrogen $\mathrm{O}$...H-bonds between $\mathrm{H}_{2} \mathrm{O}$ molecules in water samples and hamster serum blood.

\section{Results}

\subsection{Routes of administration of bioinfluence (ITF and e.m. fields)}

Two types of bioinfluence experiments were conducted. The first one involved the application of bioinfluence to well-formed subcutaneous tumors with a diameter of about $1 \mathrm{~cm}$. The second one involved bioinfluence action starting simultaneously with the tumor's transplantation. Each of the hamsters was injected with $5.10^{4}$ tumor cells /in 1.0 mL PBS-buffered saline.

Figure 1 shows the manner of bioinfluence by Drossinakis with Infrared Thermal Field and e.m. waves on hamsters with experimental tumor.
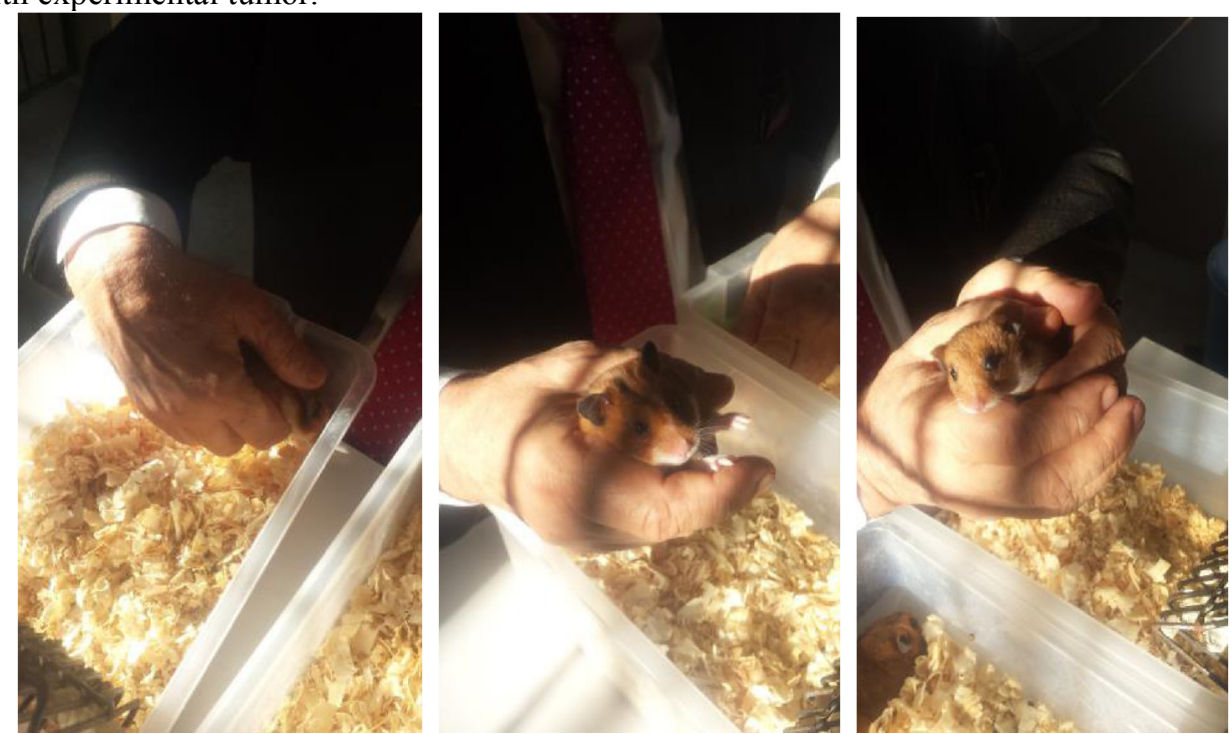

Fig.1. Bioinfluence with Infrared Thermal Field and e.m. waves on hamsters with experimental tumor In the first trial the treatment with infrared thermal field and e.m. fields started on the $10^{\text {th }}$ day after the 
injecting of tumor cells in the hamsters, were conducted in 5 consecutive days. The hamsters were separated into two groups - gr.1 with bioinfluence (ITF and e.m. waves) and gr. 2- control group - without a bioinfluence.

In the second trial, the treatment with ITF and e.m. fields were conducted in 5 consecutive days starting simultaneously with injecting the tumor cells in the hamsters. As above the hamsters were separated into two groups - gr. 3 with bioinfluence (ITF and e.m. fields), and gr.4- control group - without a bioinfluence.

\subsection{Examined tumor growth parameter}

Following parameters have been examined in the course of experiments (Figure 2. A, B, C, D).

Transplantability percent. It is evaluated as the ratio between the number of hamsters that have developed tumor and the total number of transplanted/injected hamsters with tumor cells. This parameter was calculated only for the second trial, where the bioinfluence has started on the day of tumor cells injecting.

Tumor size ( $\mathbf{m m})$. It was defined as the average diameter based on the measurement of two mutually perpendicular diameters of tumor (A-width and B-length) with caliper on regular intervals of time after the transplantation of tumor cells.

Lethality/mortality rate was evaluated as the number of died animals to the total number of hamsters in the group in percent.

Average survival rate (ASR) was calculated in days for the respective group Survival rate - chart of survival rate in the groups

\subsection{Results from the First trial are depicted in Fig. 2.}

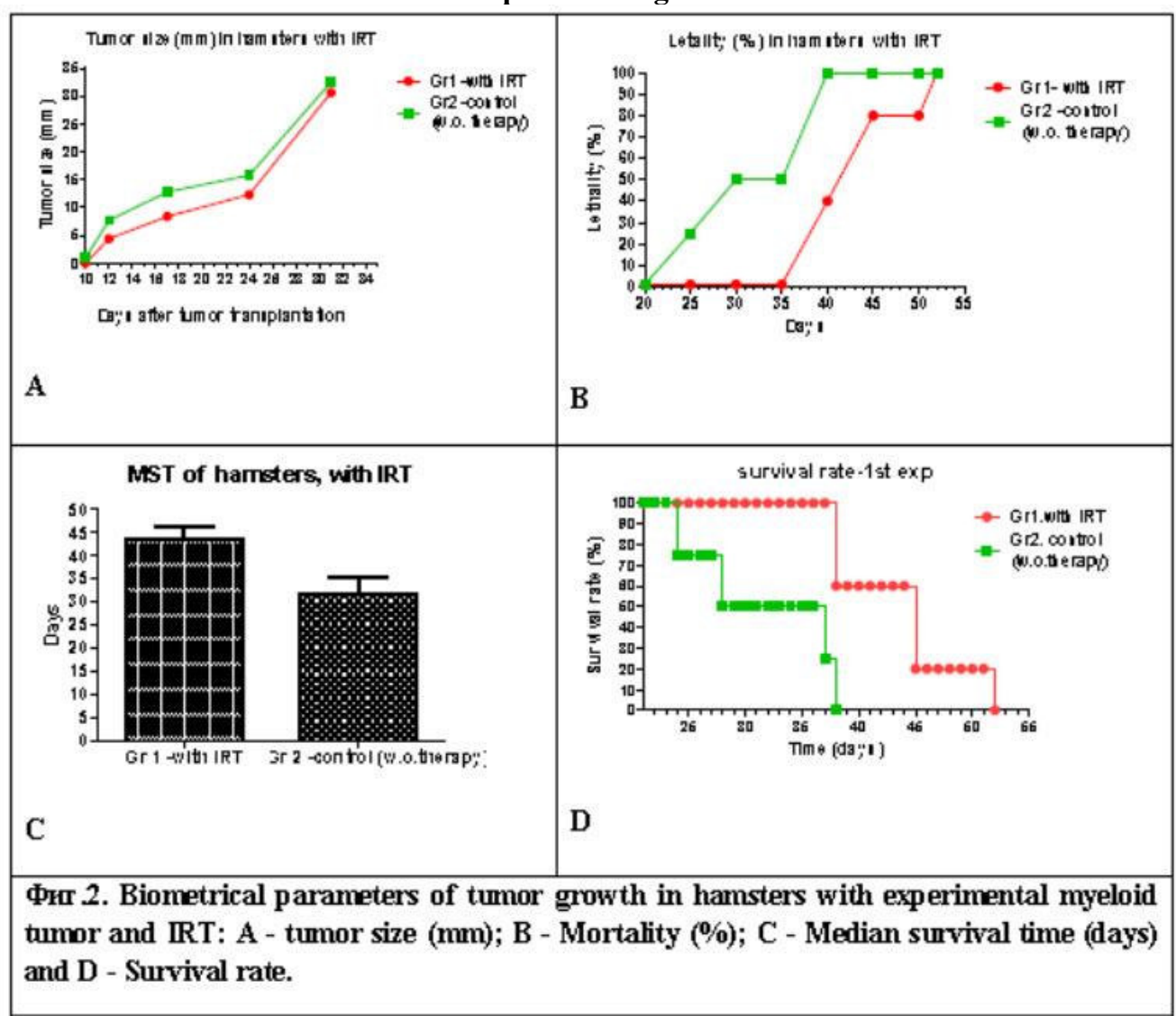

The size of the developed tumors was measured and compared to that of the control animals. As shown in Fig. 2, A the size of tumor in hamsters with ITF and e.m. fields (gr.1) was insignificantly smaller between 12-24 day in comparison with that of control group (gr. 2). Around the 30th day the tumors of the two groups are aligned in size.

Lethality rate (expressed in \%) was demonstrated in fig. 2, B. In both groups significant difference was observed. For hamsters with bioinfluence (gr. 1) low mortality rate compared to the control group (gr. 2) was established. Until the 35th day, mortality was 0 , at day $40-40 \%$, at day 45 was $80 \%$, and at day 50 it was $100 \%$. At the same time in the control group (gr.2)-the lethality was $50 \%$ on the $30^{\text {th }}$ day and reached $100 \%$ on the $38^{\text {th }}$ day.

The average survival rate of hamsters with therapy (gr.1) was $43.6 \pm 5.8$ days, for control group-without therapy (gr. 2) - 31.75 \pm 6.8 days (fig.2, C), which was 12 days longer than the controls. 
The chart in fig.2, D shows the extended survival rate for hamsters with therapy (gr. 1) in comparison with control group-without therapy (gr. 2).

Photographs of hamsters from gr. 1 (with ITF and e.m. fields) and gr. 2 (control group) in Fig. 3 illustrate the above results. They are taken on the $17^{\text {th }}$ and the $32^{\text {nd }}$ days after tumor transplantation in gr. 1 (Fig. 3, A, A1) with bioinfluence therapy, and control gr.2 (Fig. 3,B, B1) without therapy.

The conclusion we can draw from the obtained results is that bioinfluence therapy (in this scheme of application and duration) in hamsters with developed tumor doesn't stop the tumor growth (Fig.3, A), but delayed its progression, decreased lethality and prolonged average survival time.

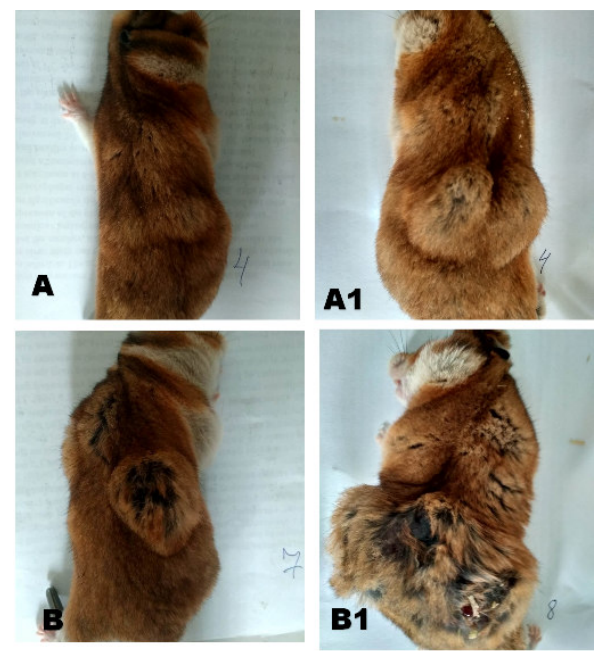

Fig.3. Pictures of hamsters from gr. 1 (with ITF) (top line) and gr.2 (control group without bioinfluence) (bottom line) on the $17^{\text {th }}$ and $32^{\text {nd }}$ day respectively.

\subsection{Results from Second trial are depicted in Fig. 5.}

Similar results are obtained in the second trial. Small differences concern the appearance of tumors in hamsters which was established through daily inspection and palpation (touching) of the site, where the tumor cells have been injected following the $5^{\text {th }}$ day after injection. Initially, at the spot of injection some firmness has been palpated that gradually was increasing, and when it reached around $10 \mathrm{~mm}$ in size it can be measured with caliper Fig. 4.

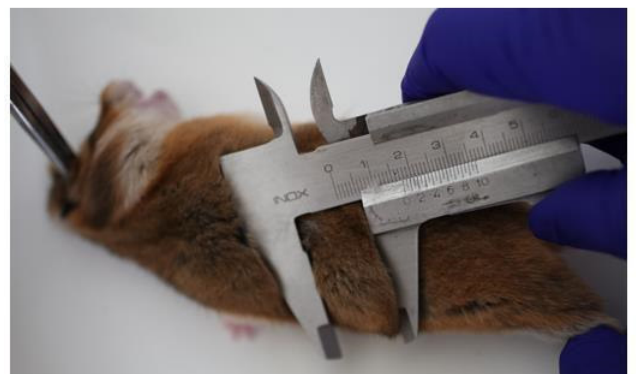

Fig. 4. Tumor size measurement 


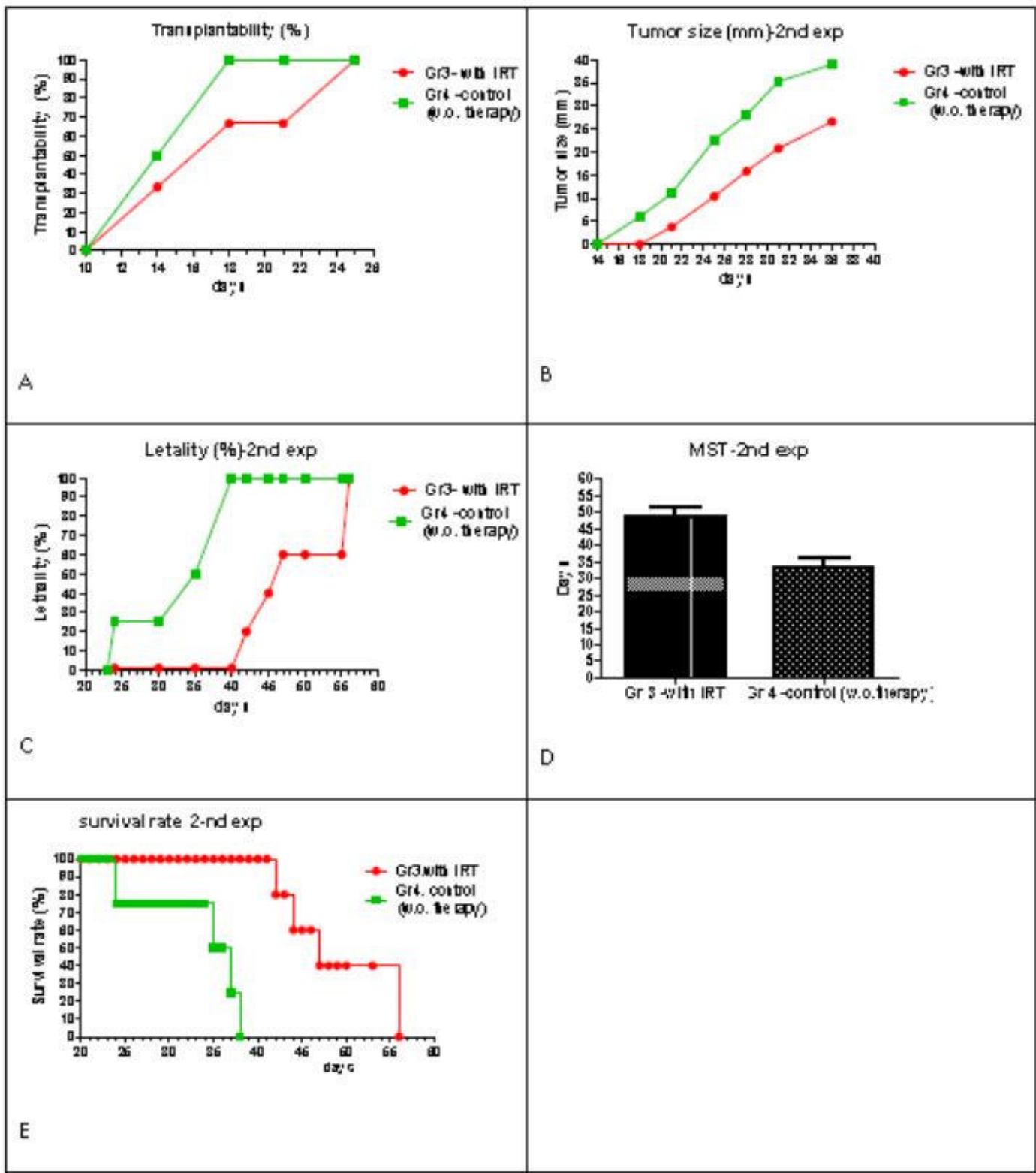

Fig. 5. Biometrical parameters of tumor growth in hamsters with experimental myeloid tumor and IRT: A - Transplantability (=tumor apperiance); B - tumor size (mm); C - Mortality (\%); D - Median survival rate (days), and E - Survival rate.

Transplantability is monitored up to 28 days after the injecting of tumor cells in both groups (gr. 3 and gr. 4). Results are shown in fig. 5, A. It can be seen from graph that the transplantability is lower in hamsters with ITF and e.m. waves (gr. 3 ) up to day 28 , in comparison with the control group-without bioinfluence (gr. 4). The reported values for gr. 3 are: on the $14^{\text {th }}$ day $33 \%$ of the hamsters developed tumors, on the $18^{\text {th }}$ day $-66 \%$, and on $28^{\text {th }}$ day $100 \%$. Unlike them, in the control group of hamsters without bioinfluence (gr. 4) $50 \%$ of hamsters developed tumor on the $14^{\text {th }}$ day and $100 \%$ on the $18^{\text {th }}$ day.

Tumor size was monitored until day 36 (Fig.5, B). Tumor size in the control group (gr. 4) was about 2 times higher than that measured in hamsters with applied ITF (gr-3) throughout the study period.

The lethality (\%) in experimental (gr. 3) and control (gr. 4) hamsters has been reported following the $23^{\text {rd }}$ day from the beginning of experiment and was presented on fig. 4. C. High mortality rate in hamsters from gr. $4-$ on the $24^{\text {th }}$ day $-25 \%$, on the $35^{\text {th }}$ day $-50 \%$, and on $38^{\text {th }}$ day $-100 \%$ death was observed. For hamsters with ITF and e.m. waves on the $42^{\text {nd }}$ day $-20 \%$, on the $45^{\text {th }}$ day $-40 \%$, on $47^{\text {th }}$ day $-60 \%$, and on $56^{\text {th }}$ day $-100 \%$ was calculated.

The average survival time (AST) of hamsters with ITF (gr. 3) has been established compared to the control group untreated animals (gr.4) (Fig. 5, D,E). From the chart (Fig. 5, D) was clearly visible that the hamsters from gr. 3 survive $49.0 \pm 6.63$ days, and from gr. 4 - 33.25 \pm 6.29 days, which was around 16 days in favor of hamsters with ITF. The hamsters from gr. 3 with applied 5 days of ITF survive for over 45 days, and $40 \%$ of hamsters 
survive 56 days (Fig. 5, E).

To support the obtained results we have presented photographs of hamsters from gr. 3 (with ITF and e.m. fields) and gr. 4 (control group) - which present the picture on the $7^{\text {th }}$ and the $23^{\text {rd }}$ day after the transplantation of tumor cells in gr. 3 (Fig. 6, C, C1) with bioinfluence, and control gr. 4 (Fig. 6, D, D1) at the same days of investigation.
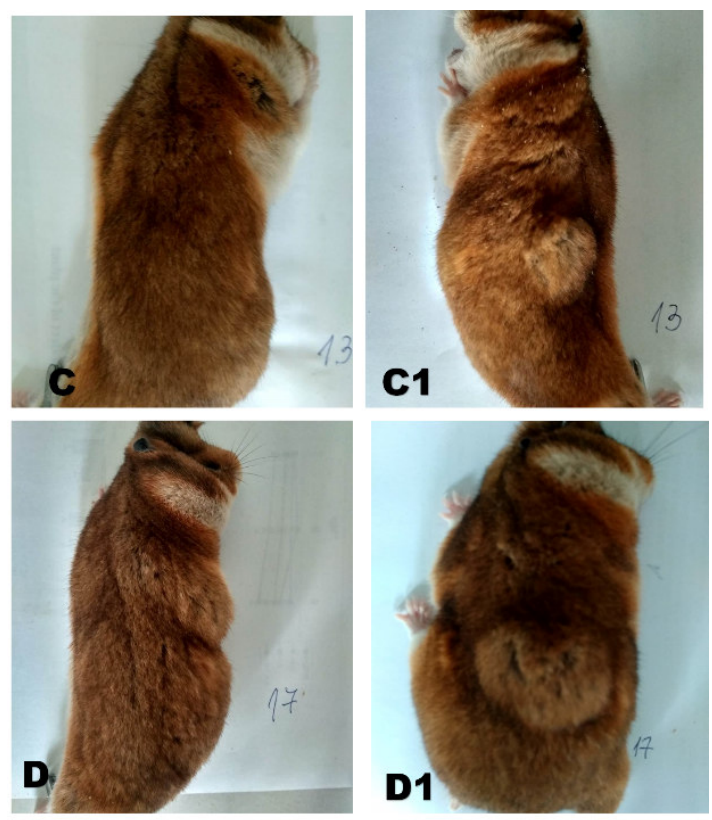

Fig. 6. Pictures of hamsters from gr. 3 (with ITF) (top line) and gr. 4 (control group without bioinfluence) (bottom line) respective to the days of investigation.

The presented photographs of hamsters from experimental groups on the 7 th and the $23^{\text {rd }}$ day from the beginning of trial, show delay in appearance of tumors and lesser size tumors in hamsters with applied ITF and e.m. waves therapy (Fig. 6. C, D), which was shown numerically and graphically in the calculated biometrical parameters of tumor - transplantability and tumor size on Fig. 5. A and Fig. 5. B.

Based on the results obtained in the second type experiments, we can draw the following conclusion: The application of ITF and e.m. waves in 5 consecutive days at the same time with injecting of tumor in trial hamsters revealed lowered percent of appearance of tumor, decreased percent of mortality, slowed tumor growth, increased survival rate and prolonged average survival time in group (gr. 3) in comparison with the same indicators for the control group - untreated hamsters with tumor (gr. 4).

\subsection{Hematological research}

Cytological differences in the erythrocyte /RBCs-/ morphology and differentiation were noticed in the blood smears of control /untreated-/, vs bio-influenced hamsters with implanted myeloid tumours of Graffi as shown in Fig. 7. A, B, C.

The observed differences probably indicate positive effects of the near infrared bio-influence on the erythropoiesis of Graffi tumour-bearing hamsters, that may lead to improvement of the anemia-syndrome obligatory developed in this and/or in other experimental models of myeloid malignancies. However, more experiments are required for a definite inference.

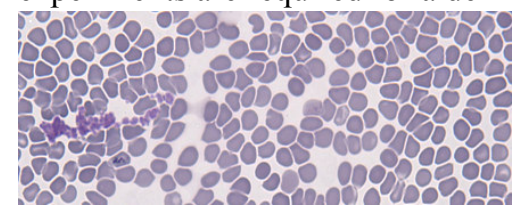

A)

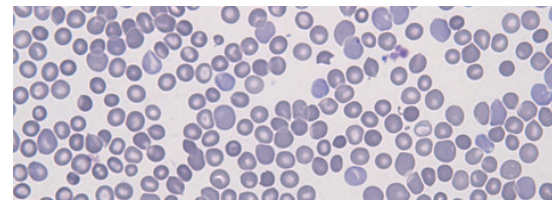

B)

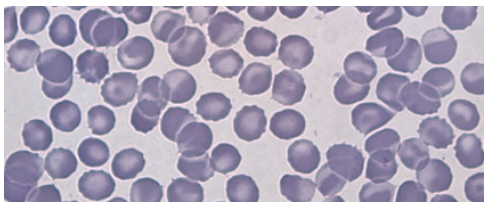

C)

Fig. 7 . A) Control healthy (x20); B) Control tumor (x 20); C) Tumor with therapy (x40)

\subsection{Results with spectral analysis with methods NES and DNES of 1\% solutions of blood serums of} hamsters

NES and DNES of blood serums after influence of Christos Drossinakis

The research was performed with the following types of $1 \%$ solutions of blood serums

Sample $1-1 \%$ solution of blood serum of hamsters with cancer after influence of Drossinakis 
Sample $2-1 \%$ solution of blood serum of hamsters with cancer as control sample

Sample $3-1 \%$ solution of blood serum of healthy hamsters

The average energy $\left(\mathrm{E}_{\mathrm{H} . . . \mathrm{O}}\right)$ of hydrogen $\mathrm{H}$...O-bonds among individual $\mathrm{H}_{2} \mathrm{O}$ molecules in $1 \%$ solution of Sample 1 of blood serum of hamsters with cancer after influence of Drossinakis is measured at $\mathrm{E}=-0.1285 \mathrm{eV}$. The result for the Control sample 2 of $1 \%$ solution blood serum from hamsters with cancer is $E=-0.1214 \mathrm{eV}$. The results obtained with the NES method are recalculated with the DNES method as a difference of the NES (Sample 1) minus the NES (Control Sample 2) equalled the DNES spectrum of $1 \%$ solution of blood serum from hamsters. $\Delta f(E)=f($ sample 1$)-f($ control sample 2$)$

Thus, the result for $1 \%$ solution of blood serum from hamster recalculated with the DNES method is $\Delta \mathrm{E}=-0.0071 \pm 0.0011 \mathrm{eV}$.

The result shows the increasing of the values of the energy of hydrogen bonds in $1 \%$ solution of blood serum of hamsters with cancer after influence of Drossinakis regarding control sample blood serum of hamsters with cancer. The results are effects of structuring of new hydrogen bonds at $(-0.1212 \mathrm{eV})$ with common antiinflammatory effect and new hydrogen bonds at $(-0.1387 \mathrm{eV})$ with anti cancer effects. This shows restructuring of water molecules in configurations of clusters, which influence usefully on human health on molecular and cellular level.

The average energy $\left(\mathrm{E}_{\mathrm{H} \ldots \mathrm{O}}\right)$ of hydrogen $\mathrm{H}$...O-bonds among individual $\mathrm{H}_{2} \mathrm{O}$ molecules in $1 \%$ solution of Sample 1 of blood serum of hamsters with cancer after influence of Drossinakis is measured at $E=-0.1285 \mathrm{eV}$. The result for the Control sample 3 in 1\% solution of blood serum of healthy hamsters is $\mathrm{E}=-0.1250 \mathrm{eV}$. The results obtained with the NES method are recalculated with the DNES method as a difference of the NES (Sample 1) minus the NES (Control Sample 3) equalled the DNES spectrum of 1\% solution of blood serum from hamsters.

$\Delta \mathbf{f}(\mathbf{E})=\mathbf{f}($ sample 1) $-\mathbf{f}($ control sample 3)

Thus, the result for $1 \%$ solution of blood serum from hamster recalculated with the DNES method is $\Delta \mathrm{E}=-$ $0.0035 \pm 0.0011 \mathrm{eV}$. The result shows the increasing of the values of the energy of hydrogen bonds in $1 \%$ solution of blood serum of hamsters after influence of Drossinakis regarding control sample blood serum of healthy hamsters.

\subsection{Local extremums of influence of Drossinakis on hamsters}

The local extremums of water samples are detected at $\mathrm{E}=-0.1112 \mathrm{eV}, \mathrm{E}=-0.1212 \mathrm{eV}$ and $\mathrm{E}=-0.1387 \mathrm{eV}$. The value measured at $\mathrm{E}=-0.1212 \mathrm{eV}\left(\lambda=10.23 \mu \mathrm{m} ; 978 \mathrm{~cm}^{-1}\right)$ is characteristic for anti-inflammatory effect (Ignatov, Gluhchev, Karadzhov et al., 2014) The value measured at $\mathrm{E}=-0.1112 \mathrm{eV}\left(\lambda=11.15 \mu \mathrm{m} ; 897 \mathrm{~cm}^{-1}\right)$ is characteristic for the presence of $\mathrm{Ca}^{2+}$ ions in water (Antonov, 1993). The value measured at $\mathrm{E}=-0.1387 \mathrm{eV}(\lambda=8.95 \mu \mathrm{m} ; 1117$ $\mathrm{cm}^{-1}$ ) is characteristic for inhibiting the growth of tumor cells (Ignatov, Mosin, 2012). Experiments conducted by Antonov with cancer cells of mice in water demonstrated a reduction of this local extremums to a negative value in DNES spectra for the function of distribution of energies $\Delta f(E)$ (Antonov, 1993). The results of influence of Drossinakis is effect of structuring of new hydrogen bonds at $(-0.1212 \mathrm{eV})$ with common anti-inflammatory effect and new hydrogen bonds at $(-0.1387 \mathrm{eV})$ with anti tumor effects. This shows restructuring of water molecules in configurations of clusters, which influence usefully on human health on molecular and cellular level.

\subsection{Mathematical models (Ignatov, Mosin, 2013) of blood serum of hamsters.}

The research was performed with the following types of $1 \%$ solutions of blood serums

Sample $1-1 \%$ solution of blood serum of hamsters with cancer after influence of Drossinakis

Sample $2-1 \%$ solution of blood serum of hamsters with cancer as control sample

Sample $3-1 \%$ solution of blood serum of healthy hamsters

The research with the NES method of water drops is received with $1 \%$ solution of blood serum of hamsters with cancer after bio influence of Drossinakis. The mathematical models of $1 \%$ solutions of blood serum of hamsters with cancer after bio influence of Drossinakis give the valuable information for the possible number of hydrogen bonds as percent of $\mathrm{H}_{2} \mathrm{O}$ molecules with different values of distribution of energies according two control samples (Table 1; Figure 7). Sample 2 is $1 \%$ solution of blood serum of hamsters with cancer as control sample. Sample $3-1 \%$ solution of blood serum of healthy hamsters

These distributions are basically connected with the restructuring of $\mathrm{H}_{2} \mathrm{O}$ molecules having the same energies.

$\mathrm{E}=-0.1112 \mathrm{eV}$ is the local extremum for effect on the nervous system

$\mathrm{E}=-0.1212 \mathrm{eV}$ is the local extremum for anti-inflammatory effect

$\mathrm{E}=-0.1387 \mathrm{eV}$ is the local extremum for inhibition of development of tumor cells of molecular level 
Table 1. The distribution $\left(\%,\left(-\mathrm{E}_{\text {value }}\right) /\left(-\mathrm{E}_{\text {total value }}\right)\right.$ of $\mathrm{H}_{2} \mathrm{O}$ molecules in water samples from Blood Serum of Hamsters. Author: Ignat Ignatov

\begin{tabular}{|c|c|c|c|c|c|c|c|}
\hline $\begin{array}{c}- \\
\mathrm{E}(\mathrm{eV}) \\
\mathrm{x} \text {-axis }\end{array}$ & $\begin{array}{c}1 \% \text { Water } \\
\text { Solution of } \\
\text { Blood Serum of } \\
\text { hamsters with } \\
\text { cancer after } \\
\text { Drossinakis } \\
\text { influence } \\
\text { y-axis } \\
\left(\%\left(\left(-E_{\text {value }}\right) * /\right.\right. \\
\left(-E_{\text {total value }}\right)^{* *}\end{array}$ & $\begin{array}{c}\text { Control } \\
\text { Sample of } \\
\text { Blood } \\
\text { Serum of } \\
\text { hamsters } \\
\text { with } \\
\text { cancer } \\
(\%((- \\
\left.E_{\text {value }}\right)^{* /} \\
\left(-E_{\text {total }}\right. \\
\text { value })^{* *}\end{array}$ & $\begin{array}{l}\text { Control } \\
\text { Sample of } \\
\text { Blood } \\
\text { Serum of } \\
\text { healthy } \\
\text { hamsters } \\
(\%((- \\
\left.E_{\text {value }}\right)^{* /} \\
\left(-E_{\text {total }}\right. \\
\text { value })^{* *}\end{array}$ & $\begin{array}{c}- \\
\mathrm{E}(\mathrm{eV}) \\
\mathrm{x} \text {-axis }\end{array}$ & $\begin{array}{c}1 \% \text { Water } \\
\text { Solution of } \\
\text { Blood Serum of } \\
\text { hamsters with } \\
\text { cancer after } \\
\text { Drossinakis } \\
\text { influence } \\
\text { y-axis } \\
\left(\%\left(\left(-E_{\text {value }}\right) * /\right.\right. \\
\left(-E_{\text {total value }}\right)^{* *}\end{array}$ & $\begin{array}{c}\text { Control } \\
\text { Sample of } \\
\text { Blood } \\
\text { Serum of } \\
\text { hamsters } \\
\text { with } \\
\text { cancer } \\
(\%((- \\
\left.E_{\text {value }}\right)^{* /} \\
\left(-E_{\text {total }}\right. \\
\text { value })^{* *}\end{array}$ & $\begin{array}{l}\text { Control } \\
\text { Sample of } \\
\text { Blood } \\
\text { Serum of } \\
\text { healthy } \\
\text { hamsters } \\
(\%((- \\
\left.\mathrm{E}_{\text {value }}\right)^{* /} \\
\left(-\mathrm{E}_{\text {total }}\right. \\
\text { value })^{* *}\end{array}$ \\
\hline 0.0937 & 0 & 0 & 0 & 0.1187 & 0 & 0 & 6.7 \\
\hline 0.0962 & 0 & 0 & 0 & 0.1212 & $21.4^{2}$ & $10.5^{2}$ & $2.3^{2}$ \\
\hline 0.0987 & 0 & 0 & 0 & 0.1237 & 7.1 & 10.5 & 0 \\
\hline 0.1012 & 0 & 10.5 & 11.3 & 0.1262 & 0 & 0 & 6.7 \\
\hline 0.1037 & 0 & 0 & 0 & 0.1287 & 7.1 & 0 & 11.3 \\
\hline 0.1062 & 0 & 105. & 0 & 0.1312 & 7.1 & 10.5 & 6.7 \\
\hline 0.1087 & 0 & 0 & 0 & 0.1337 & 7.1 & 10.5 & 18.5 \\
\hline 0.1112 & $0^{1}$ & $0^{1}$ & $0^{1}$ & 0.1362 & 7.1 & 5.5 & 0 \\
\hline 0.1137 & 14.3 & 105 & 6.7 & 0.1387 & $28.8^{3}$ & $10.5^{3}$ & $18.5^{3}$ \\
\hline 0.1162 & 0 & 10.5 & 11.3 & - & - & - & \\
\hline
\end{tabular}

\section{Notes:}

* The result (-E $\left.\mathrm{E}_{\mathrm{value}}\right)$ is the result of hydrogen bonds energy for one parameter of (-E)

** The result $\left(-\mathrm{E}_{\mathrm{value}}\right)$ is the total result of hydrogen bonds energy

Figure 8 shows the distribution $\left(\%,\left(-\mathrm{E}_{\text {value }}\right) /\left(-\mathrm{E}_{\text {total value }}\right)\right.$ of $\mathrm{H}_{2} \mathrm{O}$ molecules in and $1 \%$ of water solution of serums from hamsters, as follows:

(red line) - after bioinfluence of Drossinakis on hamsters with cancer

(blue line) - hamsters with cancer

(green line) - healthy hamsters

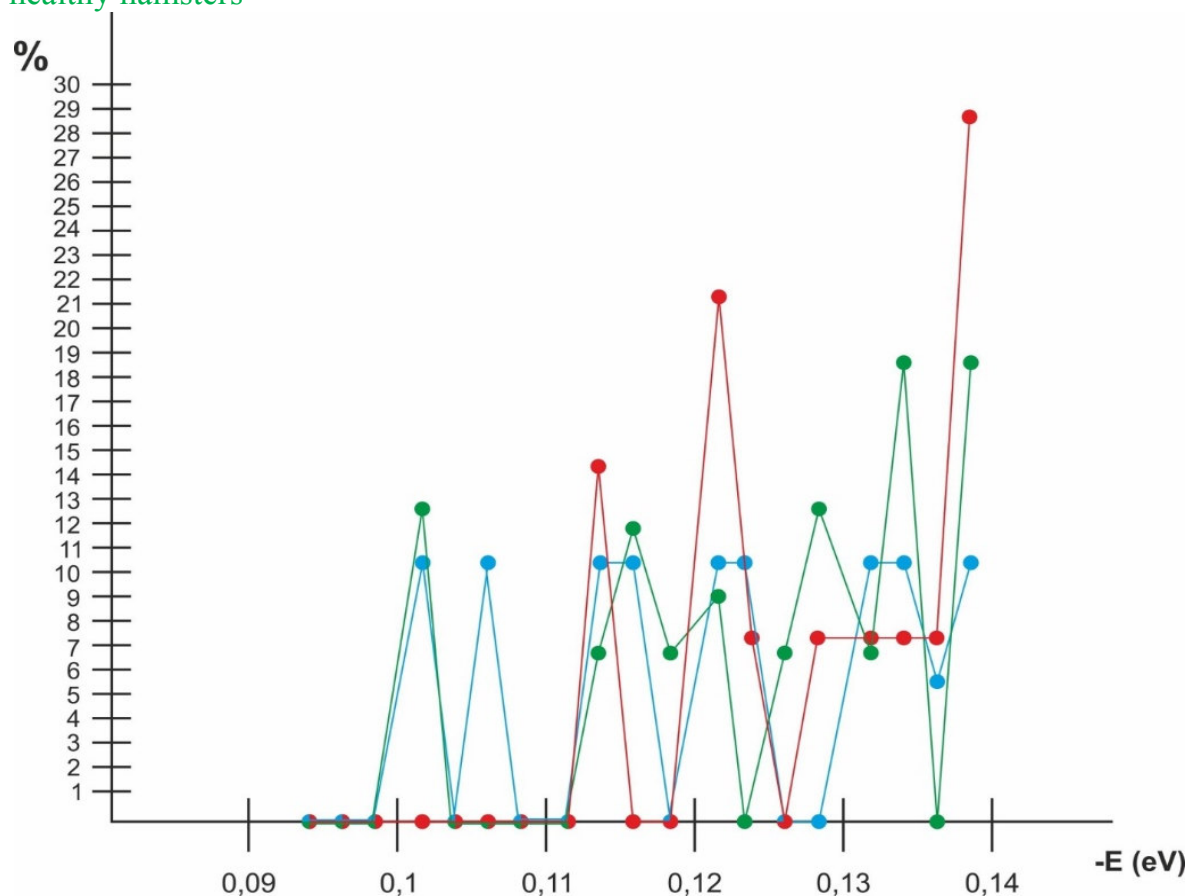

Fig. 8. Mathematical model (Ignatov, Mosin, 2013) of $1 \%$ water solutions of $1 \%$ solution of serums from hamsters.

\section{Notes:}

$\mathrm{E}=-0.1212 \mathrm{eV}$ is the local extremum for anti-inflammatory effect

$\mathrm{E}=-0.1387 \mathrm{eV}$ is the local extremum for inhibition of development of tumor cells of molecular level 


\subsection{Conclusions from mathematical models}

Sample $1-1 \%$ solution of blood serum of hamsters with cancer after influence of Drossinakis

Sample $2-1 \%$ solution of blood serum of hamsters with cancer as control sample

Sample $3-1 \%$ solution of blood serum of healthy hamsters

\subsubsection{Conclusions from mathematical models of Sample 1 with $1 \%$ solution of blood serum of hamsters with cancer after influence of Drossinakis and Sample 2 with $1 \%$ solution of blood serum of hamsters with cancer as control sample}

The obtained experimental data testify the following conclusions from the mathematical model of in Sample 1 with $1 \%$ solution of blood serum of hamsters with cancer after influence of Drossinakis and Sample 2 with $1 \%$ solution of blood serum of hamsters with cancer as control sample. The object of analysis is distribution (\%, ($\left.E_{\text {value }}\right) /\left(-E_{\text {total value }}\right)$ of water molecules in mathematical models of Sample 1 with $1 \%$ solution of blood serum of hamsters with cancer after influence of Drossinakis and Sample 2 with $1 \%$ solution of blood serum of hamsters with cancer as control sample. For the value $\mathrm{E}=-0.1212 \mathrm{eV}$ or $\lambda=10.23 \mu \mathrm{m}$ there is the bigger local extremum $\left(21.4\left(\%,\left(-\mathrm{E}_{\text {value }}\right) /\left(-\mathrm{E}_{\text {total value }}\right)\right)\right.$ corresponding to the re-structuring of hydrogen bonds among $\mathrm{H}_{2} \mathrm{O}$ molecules for anti inflammatory effect. The distribution $\left(\%,\left(-E_{\text {value }}\right) /\left(-E_{\text {total value }}\right)\right.$ of water molecules in Sample 1 according Control sample $2\left(10.5\left(\%,\left(-\mathrm{E}_{\text {value }}\right) /\left(-\mathrm{E}_{\text {total value }}\right)\right)\right.$ is different. This difference may indicate on the different number of hydrogen bonds in water samples, as well as their physical parameters, resulting in different distribution of $\mathrm{H}_{2} \mathrm{O}$ molecules and different values of $\mathrm{H}_{2} \mathrm{O}$ molecules with ratios of $\left(-\mathrm{E}_{\text {value }}\right) /\left(-\mathrm{E}_{\text {total value }}\right)$.

In particular statistical re-structuring of $\mathrm{H}_{2} \mathrm{O}$ molecules in water samples according to the energies was observed. It could be assumed that the experimental data proves the restructuring of $\mathrm{H}_{2} \mathrm{O}$ molecules on molecular level which could lead to anti-inflammatory effects with influence on the immunology system. However, for the value $\mathrm{E}=-0.1387 \mathrm{eV}$ or $\lambda=8.95 \mu \mathrm{m}$ there is biggest local extremum $\left(28.8\left(\%,\left(-\mathrm{E}_{\text {value }}\right) /\left(-\mathrm{E}_{\text {total value }}\right)\right)\right.$ corresponding to the re-structuring of hydrogen bonds among $\mathrm{H}_{2} \mathrm{O}$ molecules for inhibition of development of tumor cells of molecular level. The distribution $\left(\%,\left(-\mathrm{E}_{\text {value }}\right) /\left(-\mathrm{E}_{\text {total value }}\right)\right.$ of water molecules in Sample 1 according Control sample $2\left(10.5\left(\%,\left(-E_{\text {value }}\right) /\left(-E_{\text {total value }}\right)\right)\right.$ is different.

The experimental data for the effect of Drossinakis may prove that $\mathrm{H}_{2} \mathrm{O}$ molecules are restructured on molecular level, and the biophysical effects are:

$\mathrm{E}=-0.1212 \mathrm{eV}$ is the local extremum for anti-inflammatory effect

$\mathrm{E}=-0.1387 \mathrm{eV}$ is the local extremum for inhibition of development of tumor cells of molecular level

\section{Conclusions}

In conclusion, the results achieved from the two types of tests with 5 days course of ITF and e.m. waves treatment of hamsters with experimental subcutaneous tumor are positive. Prolonged survival rate and decreased mortality (in the first and second trial), as well as lowered transplantability and slowed tumor growth (in the second trial) were observed. The present results are the base for conducting further tests that aim to establish the optimum regimen of bioinfluence with regards to frequency and duration of the therapeutic procedures, also valid with other experimental models.

The basic conclusion is that Drossinakis is able to increase the average energy of hydrogen bonds among water molecules in the blood of hamsters with cancer after treatment compared to the average energy of hydrogen bonds among water molecules in the blood of non-treated hamsters with cancer and healthy hamsters as control groups.

The mathematical model of blood serum solution of hamsters with cancer after the Drossinakis' influence gives significant information about the possible number of hydrogen bonds as a percent of $\mathrm{H}_{2} \mathrm{O}$ molecules with different distribution of energy relative to the same number in the two control groups.

As a result of different energies of hydrogen bonds, the surface tension of the blood serum solution of cancer hamsters is increased after the treatment relative to the control samples- This effect is connected with the preservation and increase in the energy of the biochemical processes between water molecules and biomolecules.

The achieved results of hamsters from experimental bio-influence of Christos Drossinakis reveal their biological efficiency and can be subject of future studies. Extending the life of the hamsters is an indicator of improving immune status. The obtained results correspond to recent data from the medical scientific literature for the positive effect of the near infrared irradiation on the structure and function of erythrocyte membrane in normal and pathological conditions. The mitochondrial polarity in cancer cells was found to be lower than that of normal cells. Drossinakis is increasing the mitochondrial polarity.

\section{References}

Adelman, R., Saul, R. \& Ames, B. (1988) Oxidative Damage to DNA: Relation to Species Metabolic Rate and Life Span, PNAS, 85 (8): 2706-2708.

Anderson, L.E. (1993) Biological Effect of Extremely Low Frequency Electromagnetic Fields: in vivo Studies. Am. Ind. Hig. Assoc. J., 54: 186-196. 
Antonov, A. Galabova, T. (1992) Ext. Abstr. Of the $6^{\text {th }}$ National Conference of Biomedical Physics and Engeneering, 60.

Antonov, A., Galabova, T., Todorova, L., Tomov, (1993) Observatoire de Montagne de Mussala OM2, Edit par J.P. Carbonel and J. N. Stamenov, Sofia, 113.

Barnes, F.S. \& Greenebaum, B. (eds.) (2006) CRC Handbook on Biological Effects of Electromagnetic Fields, $3 d$ Edition, Boca Raton: CRC Press, 2, 1-960.

Brubach, J.B., Mermet, A., Filabozzi, A., Gerschel, A. \& Roy, P. (2005) Signatures of the Hydrogen Bonding in the Infrared Bands of Water. J. Chem. Phys., 122: 184509.

Burger, O., Baudish, A. \&Vaupel, J. W. (2012) Human Mortality Improvement in Evolutionary Context, PNAS, 109 (44): 18210-18214.

Cleary, S.F. (1993) A Review of in vitro Studies: Low-frequency Electromagnetic Fields. J. Am. Ind. Hyg. Assoc, 54(4): 178-185.

Chang, J.J., Fisch, J. \& Popp, F.A. (eds) (1998) Biophotons. Dordrecht, Kluwer Academic Publishers, 1-417

Cohen, S. \& Popp, F.A. (1997) Biophoton Emission of the Human Body. Journal of Photochemistry and Photobiology B: Biology, 40(2): 187-189.

Edwards, R. et al. (1989) Light emission from the Human Body. Complement Med. Res., 3:16.

Eisenberg, D. \& Kauzmann, W. (1969) The Structure and Properties of Water. Oxford University Press, London. Frey, A.H. (1993) Electromagnetic Field Interactions with Biological Systems. FASEB Journal, 7(2): 272-281

Gluhchev, G., Ignatov, I. Karadzhov, S., Miloshev, G., Ivanov, N.\& Mosin, O.V. (2015) Electrochemically Activited Water. Biophysical and Biological Effects of Anolyte and Catholyte as Types of Water, Journal of Medicine, Physiology and Biophysics, 10: 1-17.

Goryainov S.V. (2012) A Model of Phase Transitions in Double-well Morse Potential: Application to Hydrogen Bond. Physica B, 407, 4233-4237.

Gulyaev, Yu.V.\& Godik, E.E. (1984) On the Possibilities of the Functional Diagnostics of the Biological Subjects Via Their Temporal Dynamics of the Infrared Images, USSR Academy Nauk Proceedings/Biophysics, 277: 1486-1491.

Gulyaev, Yu.V. \& Godik, E.E. (1990) Human and Animal Physical Fields. Scientific American, 5: 74-83.

Gulyaev, Yu.V. \& Godik, E.E. (1991) Functional Imaging of the Human Body. IEEE Engineering in Medicine and Biology, 10: 21-29.

Holzel, R. \& Lamprecht, I. (1994) Wirkungen Elektromagnetischer Felder auf Biologische Systeme, Nachrichtentech Elektron, 44(2): 28-32.

Howard, C. \& Hopps (1986) Chemical Qualities of Water that Contribute to Human Health in a Positive Way, Science of the Total Environment, 54: 207-216.

Ignatov, I., Mosin, O. V. \& Naneva, K. (2012) Water in the Human Body is Information Bearer about Longevity. Euromedica, Hanover: 110-111.

Ignatov, I., Antonov, A.\&Galabova, T. (1998) Medical Biophysics - Biophysical Fields of Man, Gea Libris, 1-71.

Ignatov, I. (2007) Energy Biomedicine, Origin of Living Matter, “Informationability” of Water, Biophysical Fields, ICH, Munich, 1-136

Ignatov I. (2012) Conference on the Physics, Chemistry and Biology of Water, Water in the Human Body is Information Bearer about Longevity, NY, Vermont Photonics.

Ignatov, I. \& Mosin, O.V. (2013) Structural Mathematical Models Describing Water Clusters. Journal of Mathematical Theory and Modeling, 3(11): 72-87.

Ignatov, I. \& Mosin, O. V. (2014) Nature of Haydrogen Bonds in Liquids and Crystals. Ice Crystal Modifications and Their Physical Characteristics, Journal of Medicine, Physiology and Biophysics, 4: 58-80.

Ignatov, I., Mosin, O.V., Velikov, B., Bauer, E. \& Tyminski, G. (2014) Research of Longevity Factors and Mountain Water as a Factor in Teteven, Yablanitsa and Ugarchin Municipalities, Lovech Region, Bulgaria, Journal of Health, Medicine and Nursing, 4: 21-36.

Ignatov, I. \& Mosin, O. V. (2014) Hydrogen Bonds among Molecules in Liquid and Solid State of Water. Modifications of Ice Crystals, Journal of Health, Medicine and Nursing, 5: 56-79.

Ignatov, I. \& Mosin, O.V. (2014b) Methods for Measurements of Water Spectrum. Differential Non-equilibrium Energy Spectrum Method (DNES), Journal of Health, Medicine and Nursing 6: 50-72.

Ignatov, I. \& Mosin, O.V. (2015) Methods for Research of Mountain and Melt Water as Factor of Longevity. Chemical Composition, NES and DNES Methods for Spectral Analysis. Effects of Calcium, Magnesium, Zinc and Manganese, Advances in Physics Theories and Applications, 44: 48-64.

Ignatov, I. \& Mosin, O.V. (2015b) Water: Solid and Liquid Phases. Nano Structures in the Water in Solid and Liquid Phases, Journal of Medicine, Physiology and Biophysics, 9: 82-109.

Ignatov, I.\&Mosin,O.V. (2015) Nanostructures in Solid and Liquid Phases of Water, Journal of Medicine, Physiology and Biophysics, 12:31-57.

Ignatov, I.\&Mosin, O. V. (2014) Isotopic Composition of Water as Main Factor for Longevity, Drug Development 
and Registration, 9 (4): 146-155.

Ignatov, I. (2018) Research of the Factors of Health and Longevity for the Population in Bulgaria, Bulgarian Journal of Public Health, 10 (3): 52-85.

Ignatov, I., Karadzhov, S., Gluhchev, G.\&Yakimov, I. (2018) Electromagnetically Activated Water - Properties and Effects, Bulgarian Journal of Public Health, 10 (4): 63-69.

Ignatov, I., Toshkova, R., Gluhchev, G.\&Drossinakis, Ch. (2019) Results of Blood Serum from Cancer Treated Hamsters with Infrared Thermal Field and Electromagnetic Fields, Journal of Health, Medicine and Nursing, 58: 101-112.

Isaacs E.D., Shukla A., Platzman P.M, et all. (2000) Compton Scattering Evidence for Covalency of the Hydrogen Bond in Ice, J. Phys. Chem. Solids, 61, 403-406.

Keutsch F. \& Saykally R. (2011) Water Clusters: Untangling the Mysteries of the Liquid, One Molecule at a Time. PNAS, 98(19), 105330-10540.

Krasnov, V.V. \& Gordetsov, A.S. (2009) Infrared spectral analysis of blood serum as level of disturbances of metabolic processes in infusion children pathology. Clinical Medicine: 83-94 [in Russian].

Kwan-Hoong, Ng. (2003) Non-ionizing Radiations - Sources, Biological Effects, Emissions and Exposures. Proceedings of the International Conference on Non-Ionizing Radiation at UNITEN (ICNIR2003). Electromagnetic Fields and Our Health. 20-22 October 2003.

Luck W., Schiöberg D. \& Ulrich S. (1980) Infared Iinvestigation of Water Structure in Desalination Membranes. J. Chem. Soc. Faraday Trans., 2(76), 136-147.

Niggli, H. (1993). Artificial Sunlight Irradiation Induces Ultra Weak Photon Emission in Human Skin Fibroblasts, Journal of Photochemistry and Photobiology B: Biology, 18 (2-3): 281-285.

Mariani, E. et al. (2006) Antioxidant Enzyme Activities in Healthy Old Subjects: Influence of Age, Gender and Zinc Status: Results from the Zincage Project, Biogerentology, 7 (5-6): 391:398.

Marino, A.A (Ed.) (1988) Modern Bioelectricity. Marieel Dekker, New York, Basel, ISBN 0-8247-7788-3.

Marinov, M. \& Ignatov, I. (2008) Color Kirlian Spectral Analysis. Color Observation with Visual Analyzer. Euromedica, Hanover, 57-59.

Miller, M.W. (1986) Extremely Low Frequency (ELF) Electric Fields: Experimental Work on Biological Effects. CRC Handbook of Biological Effects of Electromagnetic Fields, 138-168.

Malhotra, A.,\&Dhawan, D. K. (2008) Zinc Improves Antioxidative Enzymes in Red Blood Cells and Hematology in Lithium-Treated Rats, Nutr. Res., 28(1):43-50

Pasichnyk I. Everaers R. \& Maggs A.C. (2008) Simulating van der Waals-interactions in Water/HydrocarbonBased Complex Fluids. J. Phys. Chem. B, 112(6), 1761-1764.

Pauling L. (ed.) (1960) The Nature of the Chemical Bond and the Structure of Molecules and Crystals, New York: Cornell University Press.

Pocock, S.J, Shaper, A.G. \& Packham, R.F. (1981) Studies of Water Quality and Cardiovascular Disease in the United Kingdom, Sci. Total Environ., 18: 25-34. 